\title{
NEIBA
}

2018

\section{A importância da guerra das Malvinas no pensamento estratégico das Forças Armadas Brasileiras e o redirecionamento da cooperação militar com a Argentina pós-1982 Rafael Macedo da Rocha Santos}

Vínculo Institucional' ${ }^{1}$ : Doutorando em História Comparada (PPGHC-UFRJ)

\section{Resumo:}

O apoio da América do Sul aos argentinos na guerra das Malvinas (1982) representou um dos maiores legados daquele conflito. O choque angloargentino apresentou um sistema de defesa frágil do continente em relação às novas formas de ameaças militares que surgiram a partir de então. A necessidade de um desenvolvimento bélico autônomo e próprio da região fora um dos ensinamentos mais importantes trazidos aos militares brasileiros no que diz respeito às novas potencialidades de conflito. 0 objetivo desse paper é analisaras novas concepções de conflito para as Forças Armadas brasileiras pós-guerra de 1982e a aproximação militar com a Argentina.

Palavras-chaves:

segurança, regionalismo, cooperação.

\section{Abstract:}

The support of South America to the Argentines in the War of the Malvinas (1982) represented one of the major legacies of that conflict. The AngloArgentine shock presented a fragile defense system of the continent in relation to the new forms of military threats that appeared from then on. The need for autonomous military development proper to the region was one of the most important lessons brought to the Brazilian military regarding the new potentialities of conflict. The purpose of this paper is to

${ }^{1}$ Conta com apoio da CAPES, sob a forma de bolsa de pesquisa. 


\section{NEIBA}

\section{VOLUME VII}

Dossiê: SimpoRI 2018

analyze new conceptions of conflict for the post-war Brazilian Armed Forces of 1982 and the military approach with Argentina.

Keywords:

security, regionalism, cooperation. 


\section{NEIBA}

\section{Introdução}

Embora o surgimento da nação seja atribuído à datas imemoriais, sua época de nascimento ocorre por volta de 1830, momento de apogeu das revoluções liberais na Europa, e atinge seu ápice no começo do século $X X$. O Estado nacional abriu o caminho para o capitalismo com a criação do mercado, mediante o estabelecimento de espaços territoriais submetidos a autoridades impessoais e regras homogêneas.

Os movimentos intelectuais mundiais de fins do século XIX e início do século XX articulavam noções como positivismo e xenofobia na formação das nacionalidades. Essas inclinações foram essenciais para a reafirmação de uma identidade nacional, sendo muitas delas frutos de uma herança positivista europeia baseada na ordem e no progresso.

Segundo Bennedict Anderson (1994), o conceito de nacionalismo pode ser compreendido mais como uma construção do senso comum do que como uma doutrina perpetuada pelos Estados. Os nacionalismos possuem legitimidade emocional profunda a ponto de se tornarem entidades históricas inquestionáveis, mais antigas do que realmente são, pois impõe um vínculo com o passado mítico como origem em comum.

Anderson (1994) relacionava o capitalismo como condição sinequa non para o êxito desse nacionalismo, pois esse tipo de organização social fazia com que as ideias circulassem com maior rapidez, promovendo uma unidade linguística intencional.

Nesse sentido, o desenvolvimento da imprensa atuou como um fator inconsciente para a popularização e propagação do conceito de nacionalismo no senso comum. A substituição de um modo de produção agrário para uma sociedade industrializada acelerou o culto à ideia de nacional durante todo o século XIX.
A criação imaginária da nação para Anderson (1994) buscava ser um instrumento raro de unificação social em questões que não encontraram caminhos para serem resolvidos no nível da realidade, fazendo com que todos os cidadãos se conhecessem e interagissem indiretamente por meio de sentimentos coletivos.

Enquanto vários autores definiram a nação por critérios objetivos, como uma raça ou grupo étnico "compartilhando características comuns", Ernest Renan (1997) definiu-a pelo desejo de um povo de viver em conjunto. A nação tornou-se constantemente perene por depender de um "plebiscito diário" conforme defende Renan.

Renan (1997) sugere o esquecimento como característica comum entre todas as nações: "verdades indesejadas" são prejudiciais ao ideário nacional, no sentido de que escancara ações de violência e alteridade quanto à formação enquanto nação.

Ernest Renan (1997) ainda relaciona a nacionalidade com um exercício de autodeterminação comum, independente de escolhas ou vontades políticas. Por fim, Renan discorda da falta de final do movimento ao defender que o nacionalismo pode sim ter um caminho finito, como por exemplo, sendo substituído por uma comunidade de nações regionais.

De acordo com Ernest Gellner (1997), a ideia de nacionalismo está intimamente ligada à uma típica criação da era moderna, dada à necessidade de elementos morais e sociais presentes apenas em sociedades seculares, racionais e individualistas.

Gellner (1997) trata o nacionalismo como uma necessidade de sociedades pós-modernas ou contemporâneas, haja vista que era a nação era um conceito indispensável em um meio de cunho racionalista e individualista. 


\section{NEIBA}

A formação do nacionalismo moderno, por exemplo, jamais se faria com base apenas em preceitos religiosos, por exemplo: apenas sociedades seculares poderiam reclamar para si uma forma de nacionalismo contemporâneo.

Hobsbawn afirma que os nacionalismos criaram visões de alteridade de uma nação para outra: "o nacionalismo se tornou uma ideologia manejável dentro da estrutura do liberalismo burguês e compatível com ele. Um mundo de nações viria a ser um mundo liberal e um mundo liberal seria feito de nações" (HOBSBAWN, 1991: p.113).

Hobsbawn (1988) destaca ainda as especificidades desse fenômeno nacional: "O nacionalismo ataca a democracia, demole o anticlericalismo, luta contra o socialismo e solapa o pacifismo, o humanismo, o internacionalismo e o liberalismo" (p.203).

Edward Said por sua vez possui uma visão mais metropolitana da questão do nacionalismo com visões mais ligadas ao centro do sistema (nesse caso da pesquisa, o Reino Unido) do que à periferia (Argentina). Nesse sentido, concentramo-nos mais em autores que tratam diretamente de nacionalismo na América Latina como Anderson (1994).

Em termos militares, a guerra das Malvinas (1982) representou um choque bélico entre duas regiões: América do Sul e Europa. Tratou-se de um conflito norte-sul: uma grande potência com enormes recursos bélicos contra um país sul-americano com forças convencionais. Sobrepunhase assim à concepção militar leste-oeste (clássica da guerra fria) presente até então no pensamento militar de países aliados dos EUA.

Williams Gonçalves (2009) afirma que a guerra das Malvinas atuou como um conflito "intensificador de tendências para os anos 1980 e 1990". Nesse sentido, a guerra "apontou na prática o que se vinha desenhando em tecnologias e alinhamentos como orientação para os futuros governos democráticos" (GONÇALVES, 2009: p. 183).

Ricardo Pereira Cabral (2005) aponta como um dos legados da guerra das Malvinas a necessidade de construção de um sistema militar autônomo no Atlântico Sul dominado pela cooperação e pelo intercâmbio tecnológico dos países da região. Cabral ainda ressalta a urgência de aprimoramento dos dispositivos regionais militares para o fortalecimento de suas defesas coletivas em caso de enfrentamento com grandes potências.

O tema Malvinas na Argentina atual é multidisciplinar e envolve uma ampla gama de disciplinas: Geografia, História, Direito Internacional, Economia, Sociologia e Ciência Política. A temática das ilhas, ainda polêmica, desperta grandes paixões naquele país com um enorme número de trabalhos acadêmicos produzidos desde a guerra de 1982 .

Essa peculiaridade permite vislumbrar a elaboração de um trabalho historiográfico com grande viés interdisciplinar: uma História entrelaçada com conceitos essenciais e primordiais das ciências humanas como Economia, Sociologia, Relações Internacionais e Ciência Política. Nesse sentido, pretende-se abordar cada uma dessas perspectivas das ciências humanas como complementares e auxiliares entre si.

\section{Antecedentes}

A intensidade do sentimento nacional argentino sobre as Malvinas não é difícil de exagerar. Ocupadas à força pelos britânicos desde 1833, as ilhas remontam aos argentinos um passado mítico: a luta pela consolidação do território nacional contra uma grande potência, 


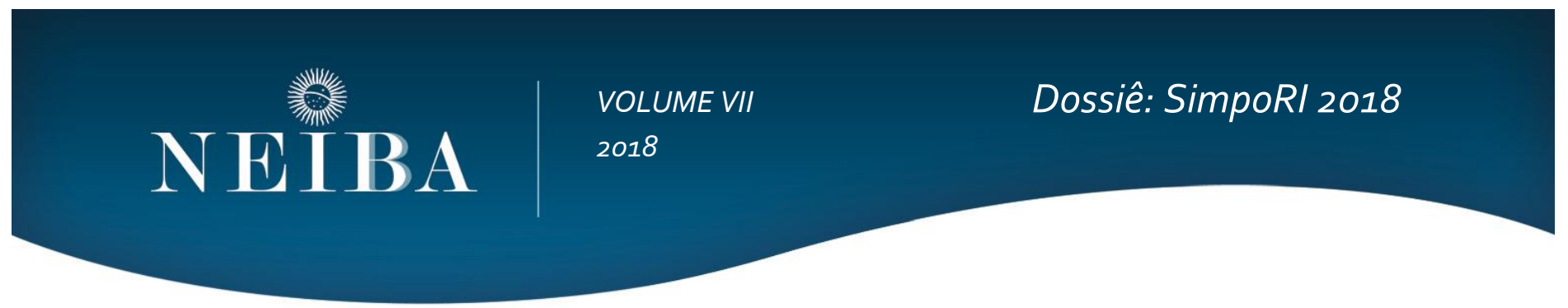

reproduzindo as lutas de independência das primeiras décadas do século XIX².

Para grande parte da sociedade argentina, a perda das ilhas responde a uma lógica arbitrária e injusta: uma grande potência imperial consolidada contra uma jovem nação em formação e envolta em guerras civis. Isso atribuiu à causa das Malvinas questões perenes como justiça e reparação, que jamais cessaram de existir no imaginário coletivo argentino.

Desde 1833, o tema oscila no imaginário popular argentino como uma "fratura permanente" que insere a nação como algo incompleto. Passava-se corriqueiramente a associar as Malvinas com a falta de independência plena argentina e a permanência constante de vínculo territorial "colonialista" com os europeus. Criava-se assim uma forma de radicalismo institucionalizado interno sobre o impasse com os britânicos.

O constante revisionismo histórico em uma sociedade politizada como na Argentina criava uma sensibilidade nacional que não se limitava somente aos militares e aos governantes: "um conjunto de sentimentos, atitudes e ideias rascunhadas (...) que revelaram uma grande capacidade de dissolver polarizações" (ROMERO, 2006: p.88).

As constantes lutas entre as mais distintas facções (sindicalistas, peronistas, socialistas, liberais, radicais e militares) se inseriam em um contexto de grande instabilidade institucional que reinou no país durante mais da metade do século XX. Diversos governos aproveitaram-se

\footnotetext{
2 As Malvinas remontavam à uma ideia de "libertação nacional" que reproduzia as lutas pela consolidação da unidade territorial. No caso argentino, a independência (1810) antecedeu em apenas 23 anos a invasão britânica às ilhas (1833). Desde então, vários choques como o bloqueio anglo-britânico ao porto de Buenos Aires (1845-1850) acirraram esse viés libertador. A construção do nacionalismo argentino seguiu essa lógica antiimperialista, algo constantemente presente na formação nacional do país do século XIX.
}

assim do grande engajamento dos argentinos em questões políticas para criar uma aparente coesão em torno de questões de unanimidade com a questão das Malvinas.

As crises políticas e econômicas ganharam protagonismo: de 1946 a 1982, a Argentina vivera quase duas décadas sob estado de sítio e assistira em média a mais de uma ruptura institucional a cada dez anos. Paulo de Queiróz Duarte (1986) afirma que a palavra "revolução" era acenada corriqueiramente entre os argentinos a partir de meados do século XX como a chave para a concretização do desenvolvimento nacional e a utilização das Forças Armadas se tornaria algo extremamente banalizado na vida política dos argentinos.

O forte engajamento civil em torno de causas nacionais e a instabilidade política crônica do país contribuíram para legitimar as Forças Armadas argentinas como instituições centrais de poder no século XX acirrando questões de "segurança nacional".

A partir de meados do século $X X$, a Argentina vê sua outrora pujante economia de fins do século XIX e início do século XX entrar em completo colapso.

Apesar de outros problemas territoriais terem sido uma constante na História argentina como o litígio em Beagle com o Chile, nenhuma questão diplomática deles atrairia tamanha atenção na opinião pública e geraria tamanha emotividade como a causa das Malvinas.

Uma canção de 1971 escrita pelo cantor argentino AthualpaYupanqui expõe essa emotividade dos argentinos com as ilhas:

De la mañana a la noche/ De la noche a la mañana/ En grandes olas azules/ $Y$ encajes de espumas blancas/ Te va llegando el saludo/ Permanente de la Pátria/ Ay, hermanita perdida/ hermanita, vuelve a casa/Malvinas, tierra cautiva/ De un rubio tiempo pirata/ Patagóniate suspira/ Toda la 


\section{NEIBA}

pampa te llama/ Seguirán las mil banderas/ Del mar, azules y blancas/ Pero queremos ver una/ Sobre tus piedras clavada/ Para llenarte de criollos/ Para curtirte la cara/ Hasta que logres el gesto[tradicional] de la Pátria/ Ay, hermanita perdida/ Hermanita: vuelve a casa. $^{3}$

Segundo Novaro e Palermo (2007), nesse interim entre os anos 1940 e 1960, muitos políticos argentinos passaram a articular as ilhas Malvinas ao destino da República, da democracia, dos tratados comerciais e até mesmo dos miseráveis do país (p. 575).

Soma-se a essa problemática, a incorporação ativa das massas como corpo político atuante na Argentina no século XX. A questão das Malvinas se enraizava na sociedade argentina como uma causa nacional absoluta repleta de valores e simbolismos pelos quais a população estava disposta a se sacrificar (NOVARO e PALERMO, 2007: p. 540).

Nesse contexto, Miriam Gomes Saraiva (2007) ressalta o histórico caráter circunstancial da política externa argentina, muito suscetível à eventos domésticos. Essa vertente de diplomacia é diferente do seu vizinho Brasil, cuja orientação de política externa (Itamaraty) é praticamente alheia a pressões sociais internas.

A definição das ilhas como prioridade absoluta da política externa argentina fora extremamente influenciada por eventos domésticos constituídos a partir de meados do século $X X$, independentemente do valor estratégico ou econômico do arquipélago.

Rudzit e Nagomi (2010) defendem que o próprio conceito de segurança é político e levam em conta a legitimidade de um regime político e os baixos níveis de

3 https://www.youtube.com/watch?v=-6-HWbczzjo consultado em agosto de 2018. coesão social internas. Cada conceito de segurança é peculiar, sobretudo, em termos de particularidades domésticas.

A tônica tradicional da política externa, teoricamente pautada na busca por segurança nacional, é relativizada na questão das Malvinas. Essa relativização da teoria realista da segurança é objeto de diversos estudos em relações internacionais recentes, que tratam da pressão de grupos sociais específicos em detrimento do "interesse nacional" coletivo.

Em relação às peculiaridades da Argentina na cena internacional, nos baseamos nas análises de Ana Luíza Bravo (2016) que trata da existência de Estados mais realistas e Estados menos realistas. A Argentina seria um Estado menos realista, cujo comportamento no cenário externo se basearia mais em variáveis internas do que a média internacional.

Em relação à segunda hipótese, destacamos como "verdade provisória" a recorrência maior às Malvinas vindas de governos ilegítimos, tanto de esquerda como de direita. Quanto maior a constitucionalidade e legitimidade de um governo, sobretudo os mais liberais economicamente, menores as chances de utilização das ilhas como válvula de escape.

Essa relação entre "política externa de Estado" e "política externa de governo" sempre se demonstrou ser muito confusa na Argentina. A instabilidade política interna aprofundará ainda mais essa articulação, evidenciada na causa das Malvinas.

Entender a formação do interesse nacional argentino sobre as Malvinas requer uma análise introdutória sobre conceitos como imperialismo, colonialismo e dependência, premissas nas quais os argentinos se basearão em suas reclamações diplomáticas.

A existência de uma identidade cultural propriamente argentina merece por só uma introdução, já 


\section{NEIBA}

que atuará como "biombo justificador" para a atuação diplomática no plano exterior. Assim se buscará articular as gestões diplomáticas dos governos argentinos com as crises internas, atuando uma sobre a outra como condicionantes entre si.

As sucessivas crises políticas e econômicas precipitaram um aumento do papel do Estado na vida social entre 1946 e 1982. Essas intervenções constantes levaram ao controle de mentes e paixões argentinas por governos militares com forte viés nacionalista.

Nesse sentido, nacionalismo e imperialismo atuaram como condicionantes entre si em movimentos de emancipação na América Latina. Contextualmente, essa noção se reproduziu no caso da formação nacional argentina e especificamente na questão das ilhas.

Dessa forma, em busca de novos apoios, os argentinos alegavam que as Malvinas não eram apenas uma questão nacional, mas também uma causa regional latinoamericana. Essa tese permeou a atuação argentina sobretudo em foros interamericanos.

Algumas variantes coloniais como o imperialismo são objetos de estudos recorrentes no meio acadêmico como quando se relaciona nacionalismo ao chamado Terceiro Mundo.

Com esse tipo de discurso, os argentinos buscaram apoio em instituições internacionais latino-americanistas e terceiro-mundistas que reconheciam a luta anticolonial do país.

A junção entre fenômenos como populismo e nacionalismo ajudavam a articular uma vertente de reivindicações populares, que eram corroboradas pelos próprios dirigentes do país. O discurso anti-imperialista começou a frequentar as retóricas de radicais, socialistas, sindicalistas e intelectuais (ROMERO, 2006: p. 67).
Esse novo nacionalismo pós-1940 era o único movimento capaz de aglutinar grupos políticos de direita e esquerda na Argentina sob uma única bandeira. $O$ ataque à democracia, ao liberalismo e ao comunismo se inseria em uma lógica de ocorrência de ditaduras militares disseminadas na Argentina ao longo do século XX.

Essa argentinidade, portanto, tornou-se o único sentimento unânime e consensual entre as mais diversas correntes políticas do país no século XX. Segundo a esquerda, esse vazio de influência gerou relevantes mudanças sociais, acelerando mecanismos institucionais ideológicos nacionalistas de controle de classes sociais menos favorecidas como o peronismo.

Tantos os regimes de esquerda quanto os de direita recorreram às Malvinas no plano externo. Vários governos (constitucionais, golpistas, transitórios, democráticos, esquerdistas e direitistas) incentivaram no senso comum a ideia de que apenas uma Argentina unida seria capaz de fortalecer o país na recuperação das ilhas:

O sentimento nacional de desagravo à sua bandeira, com o perpassar dos anos, foi avolumandose e ganhou forma, ensinado à juventude argentina desde os bancos das escolas primárias, onde livros e mestres sustentavam continuadamente que as Malvinas eram argentinas. $E$ esse desagravo que aguardava sua vez para ser desfechado passou sem grande esforço aos chefes do país (...) passando a constituir uma espécie de obsessão coletiva que, impaciente, aguardava uma oportunidade (DUARTE, 1986: pp. 29-30)

Nesse sentido, a radicalização da sociedade e a militarização interna acompanham de perto a evolução política das negociações sobre as ilhas como uma espécie de "termômetro" entre as crises domésticas e as pressões diplomáticas argentinas sobre a transferência de soberania das ilhas nos organismos internacionais. 


\section{NEIBA}

O respaldo de organizações interamericanas e terceiro-mundistas aos argentinos fora praticamente consensual. Diante da falta de resultados de notas diplomáticas trocadas diretamente com os britânicos, os argentinos passam a se concentrar então na legitimidade de seus direitos sobre o arquipélago em organismos internacionais.

A coesão nacional difícil de ser atingida em um ambiente interno seria alcançada apenas através de inimigo externo comum, com características que remontavam à própria formação nacional argentina: a luta contra uma grande potência por sua consolidação territorial. A causa, portanto, era praticamente um consenso entre os argentinos e a própria diplomacia.

Os argentinos alegavam em seus despachos diplomáticos que as ilhas eram heranças coloniais, argumento que ganhou força em um contexto de descolonização entre os anos 1950 e 1970. Já os britânicos defendiam o princípio de autodeterminação dos 3 mil ilhéus: 98\% deles desejavam permanecer súditos do Reino Unido em vários referendos.

Os reclames incluem até notas diplomáticas argentinas em organismos internacionais sem relação direta com o imbróglio como União Africana e Liga Árabe buscando apoios diplomáticos. O lobby argentino para a causa incluía até vantagens em tratados comerciais em caso de reconhecimento da soberania argentina sobre as ilhas.

\section{O pensamento geoestratégico e geopolítico do}

\section{Brasil na guerra das Malvinas}

De forma geral praticamente todos os países da América do Sul apoiaram os direitos argentinos sobre as ilhas Malvinas durante o conflito. Com exceção do Chile de Pinochet $^{4}$, que se posicionou a favor dos britânicos, as

\footnotetext{
$4 \mathrm{O}$ impasse sobre as ilhas do Canal de Beagle que quase levou à guerra entre argentinos e chilenos em 1978 ainda afetava consideravelmente as
}

reuniões de consultas realizadas pela OEA contaram recorrentemente com apoio maciço dos países continentais à causa argentina.

A representação de proposições dos argentinos no Conselho de Segurança da ONU, por exemplo, era realizada pelo Panamá, único latino-americano rotativo presente no órgão à época da guerra. Quando da condenação argentina à invasão de dois de abril de 1982 (Resolução 502), o Panamá fora o único voto contrário cujo resultado fora 10 a 1.

A unidade (pelo menos política) do continente em torno da Argentina no imbróglio das Malvinas indicava uma tendência cooperativa que o desenrolar da guerra apenas enfatizaria. Mesmo sem efeitos práticos em auxílio aos argentinos acuados, esse apoio diplomático corroborou os vínculos de cooperação entre os países sul-americanos.

Em artigo ao Jornal do Brasil, o cientista político Hélio Jaguaribe antecipava um pensamento consensual que dominaria não apenas o Itamaraty, mas também sintetizaria a concepção dos círculos militares brasileiros durante a guerra das Malvinas (1982): a necessidade de proteger o sistema interamericano de interferências externas, mesmo com o enfraquecimento do Tratado Interamericano de Assistência Recíproca (1947), o principal sistema de defesa dos sul-americanos desde o fim da Segunda Guerra Mundial:

O chanceler Saraiva Guerreiro em seu livro de memórias assumiu que a preocupação dos estrategistas brasileiros com a segurança continental americana fora uma constante:

Era de toda conveniência [deixar claro aos EUA] que se eles não conseguissem parar a frota britânica para negociar, pelo menos, a Grã-Bretanha

relações bilaterais. O modelo econômico chileno ("Ladrilho") pós-1973, menos voltado à integração regional e mais direcionado às relações com as grandes potências se confirmou por exemplo quando da retirada chilena do Pacto Andino em 1976. Os chilenos temiam que se a aventura argentina nas Malvinas fosse premiada, o próximo alvo seria o Chile. 


\section{NEIBA}

evitasse bombardear cidades argentinas ou praticar qualquer ato de agressão contra o território continental americano. Se houvesse algum ataque assim, os latino-americanos que estavam dando apoio à Argentina em suas reclamações, mas evitando agir explicitamente, seriam obrigados a reagir muito além de suas intenções. (...). Parece-me que Reagan telefonou para a Sra. Thatcher para pressioná-la, mas sem obter qualquer garantia ou promessa. Felizmente, as circunstâncias excluíram a ocorrência da pior hipótese. (GUERREIRO, 1992: p. 106).

O chanceler Saraiva Guerreiro fora extremamente criticado pelos britânicos quando soltara uma nota chamando a invasão argentina de "ação" ao invés de "agressão", o que visava retirar a Argentina da condição de "Estado agressor".

De acordo com a Revista "Veja" de 16 de junho de 1982, os Ministros da Marinha, Exército e da Aeronáutica passaram em média 16 horas por dia discutindo os ensinamentos da guerra das Malvinas para as Forças Armadas brasileiras. Novas táticas e o desenrolar das batalhas foram analisados minuciosamente pelos chefes militares.

De fato, o sub-chefe do Departamento de Ensino e Pesquisa do Exército, general Octávio Costa, dissera no final da crise, que o conflito das Malvinas fora o acontecimento militar mais importante para a formulação do pensamento estratégico das Forças Armadas brasileiras em toda a segunda metade do século XX.

Tradicionalmente, os militares brasileiros concebiam uma hipótese de conflito com apoio dos Estados Unidos sob a tutela do TIAR provavelmente contra um aliado ou satélite da URSS. Até o final dos anos 1970, a Argentina ainda constava na agenda de ameaças brasileiras, sobretudo, por conta das antigas disputas ao redor das usinas hidrelétricas de Itaipu-Corpus, resolvidas apenas em 1980.

O evento nas Malvinas trouxe um pessimismo latente entre os oficiais mais graduados das Forças Armadas brasileiras. Seus depoimentos estão impregnados por um "realismo sombrio" vindo dos desdobramentos do conflito anglo-argentino. De fato, boa parte da doutrina das escolas militares brasileiras precisou ser repensada.

A presença de uma poderosa esquadra de um país intercontinental no Atlântico Sul era apontada como um fator perigosos para a própria segurança da América do Sul na visão do Contra-Almirante Mário César Flores: "infelizmente, assim como no passado, continuamos sob a influência das grandes potências (...). Todo o modelo econômico brasileiro depende da tranquilidade do Atlântico Sul" (Jornal do Brasil, 17/04/1982).

Entre os militares brasileiros, uma enorme decepção com os EUA tomou conta dos quartéis após a guerra das Malvinas. Segundo o general Costa: "os tradicionais aliados hemisféricos e parceiros incontestáveis do país [os EUA] deixaram bem claro que a Europa era muito mais importante do que a América Latina. Teríamos que nos virar sozinhos, pois TIAR não vale muita coisa" (Jornal do Brasil, 02/06/1982).

O Ministro da Marinha na época, Almirante Maximiano da Fonseca, perplexo com a fragilidade dos equipamentos militares brasileiros (alguns deles de tecnologia muito semelhante aos usados pelos argentinos como os caças F-5E Tiger) e com a postura dos EUA dissera após a derrota: "Ninguém pode confiar em ninguém, então, confie em si mesmo. É claro que se vier uma guerra mundial, você não vai entrar sozinho. Mas pensar que vão the proteger? Protegem coisa nenhuma!" (GONÇALVES, 2009: p. 192). 


\section{NEIBA}

O Ministro da Aeronáutica, Délio Jardim de Mattos, afirmou após a derrota argentina que o conflito das Malvinas traria grandes ensinamentos às Forças Armadas Brasileiras: mudaria a concepção dos inimigos em potencial nas "Escolas de Guerra" do país.

Era consenso entre os militares brasileiros que a Região do Prata (limítrofe à Argentina), após o conflito das Malvinas, estaria praticamente pacificada, pois o apoio brasileiro à causa argentina nas ilhas garantira uma enorme distensão. Tratava-se até então de uma região historicamente crítica com a concentração de tropas de ambos os lados (Brasil e Argentina) como forma de dissuasão e contenção mútuas.

Entre os novos cenários de guerra idealizados pelos militares brasileiros, destacam-se aqueles envolvendo uma correlação de forças semelhantes ao conflito das Malvinas (1982): o Brasil sozinho teria que se defender de uma potência extracontinental ou uma coligação delas em uma possível região de "crescentes ambições internacionais em um mundo cada vez mais carente de recursos naturais" (em referência clara à Amazônia).

Desde então, o Brasil passara a se preocupar mais com sua fronteira norte do que com as suas bases no sul. O aumento de efetivo militar na região amazônica, segundo Moniz Bandeira (1995), fora um dos reflexos diretos do conflito nas Malvinas, pois as rivalidades ao sul com os argentinos ficaram em segundo plano.

Os militares brasileiros preocuparam-se com o produto da grande coalizão militar mobilizada pela GrãBretanha, em um curto espaço de tempo, para dominar de forma um país mediano como a Argentina. Questionavamse, a partir dos acontecimentos ocorridos nas ilhas, sobre as frágeis capacidades de defesa do Brasil para fazer frente às armas utilizadas pela coligação anglo-americana.
Discutiram-se nos quarteis questões relacionadas ao fomento de uma cooperação militar sul-sul como ocorrera na guerra das Malvina se a necessidade de contatos com fornecedores de armas de países subdesenvolvidos, haja visto o forte embargo de apetrechos sofrido pela Argentina vindo das nações ricas durante a guerra.

Os militares brasileiros preocupavam-se também com a reposição do farto material bélico perdido pela Argentina durante o conflito com os britânicos. De fato, a histórica rivalidade Brasil-Argentina que vinha desde o século XIX daria lugar à possibilidade de um promissor intercâmbio militar a partir dos anos 1980.

Diversos empresários brasileiros emitiram um comunicado conjunto à imprensa após a guerra condenando o embargo de produtos militares contra os argentinos. João Camargo, vinculado ao ministério de Comércio Exterior do regime militar, dissera que:

É preciso ver em que medidas o Brasil poderá transferir para a Argentina as compras que eles faziam no exterior quando foram sancionados injustamente pela Comunidade Europeia. Como aconteceu agora com a Argentina, podia ter acontecido com o Brasil, por isso temos que aproveitar a oportunidade para fortalecermos de uma vez por todas a integração latino-americana. Temos condições de trocar figurinhas entre nós mesmos (DUARTE, 1986: pp. 225-226).

O conflito precipitaria assim uma importantíssima modificação de prioridades para os brasileiros, necessárias para que o país se adaptasse às novas condições do "novo" mercado de armas. Destacamos o novo intercâmbio de tecnologias militares entre Brasília e Buenos Aires: "A guerra mostrou a vantagem de ter um fornecedor de armas próximo como o Brasil. Antes da guerra, os argentinos preferiam 


\section{NEIBA}

comprar de outros fornecedores militares material idêntico produzido pelo Brasil". (DUARTE, 1986: p. 385).

\section{Conclusão}

A guerra das Malvinas continuou com uma forte tendência de cooperação e complementaridade entre Buenos Aires e Brasília, levando ambos a reverem suas doutrinas militares e inserções internacionais. Surge após o conflito a concepção de que o Brasil poderia atuar como um polo de complementação industrial militar para a Argentina, já que o armamento produzido pelos argentinos era considerado caro e defasado.

De fato, confirmou-se publicamente que o Brasil havia cedido dois aviões de patrulha EMB-111 aos argentinos por US\$ 7 milhões cada. O fornecimento de material bélico brasileiro também envolveu operações secretas de cessão de aviões Xavantes, foguetes balísticos ar-terra e tanques leves, fornecidos pela Cascável ao longo da crise.

Outros apetrechos militares como bombas e mísseis da Avibrás e da D. F. Vasconcelos seriam fornecidos aos argentinos ao longo dos anos 1980 como consequência direta da cooperação argentino-brasileira na guerra contra os britânicos.

Em outubro de 1984, dois anos e meio após a guerra das Malvinas, o chefe do gabinete militar do presidente Figueiredo, general Rubem Ludwig, confirmou uma venda expressiva de tanques da Engesa aos argentinos. Essa aquisição fora corroborada pelo próprio Exército argentino, que prometera novas aquisições nos próximos anos.

Confirmava-se assim o início de uma cooperação militar bilateral, resultado sobretudo dos desdobramentos verificados na guerra das Malvinas. Os acordos de Iguaçu, firmados já durante a redemocratização de ambos os países em 1985, seriam apenas um dos desdobramentos de uma série de acontecimentos, onde a guerra das Malvinas se insere como um elemento decisivo e de suma importância para as relações bilaterais.

Futuros tratados como o Mercosul seriam o apogeu de uma íntima relação bilateral que teve como pano de fundo a grande dose de confiança e diminuição de rivalidades geradas pelo conflito anglo-argentino. 


\section{NEIBA}

VOLUME VII

Dossiê: SimpoRI 2018

2018

\section{BIBLIOGRAFIA}

ANDERSON, Bennedict. Imagined Communities. Londres: Verso, 1994.

AYERBE, Luís Fernando. Estados Unidos e América Latina. São Paulo: Unesp, 2002.

BALESTRINI, Alberto (org.). Pensar Malvinas. Buenos Aires: Observatório Parlamentário de laCuestión Malvinas, Senado Federal, 2007. BALZA, Martín. Malvinas, Gesta e Incompeténcia. Buenos Aires: Atlántida, 2003.

BANDEIRA, Moniz. Estado Nacional e Política Internacional na América Latina. Brasília: UnB, 1995.

BARBÉ, Esther. Relaciones Internacionales. Madrid: Tecnos, 1995.

BARRACLOUGH, Geoffrey. Introdução à História Contemporânea. Rio de Janeiro: Guanabara, 1986.

BARROS, José D'Assunção. História Comparada. Petrópolis: Vozes, 2014.

BETHELL, Leslie (org.). História da América Latina. São Paulo: USP, 2007.

BLOCH, Marc. Apologia da História. Rio de Janeiro: Zahar, 2001.

História e Historiadores. Lisboa: Teorema, 2001.

BOSOER. Fabián (org.). Generales e Embajadores: una história de las diplomacias paralelas en Argentina. Buenos Aires: Vergara, 2005.

BRANCO, Guilherme Castelo (org.). Terrorismo de Estado. Belo Horizonte: Autêntica, 2017.

BRAVO, Ana Luíza. Instituições de Defesa e Processo Decisório. Rio de Janeiro: Tese de Doutorado do PPGHC, 2016.

BRIGAGÃO, Clóvis. A militarização da sociedade. Rio de Janeiro: Jorge Zahar, 1985.

BUZAN, Barry, WAEVER, A. New Framework for Analysis. Boulder, C.O.:LynneReinnerPublishers, 1998.

CABRAL, Ricardo Pereira. O fim da guerra fria e as perspectivas geopolíticas e geoestratégicas para o Brasil frente à crise de segurança hemisférica (1991-2001). Rio de

Janeiro: Dissertação de Mestrado do PPGHC/UFRJ, 2005.

CABRAL, Antônio; MARTINEZ, Hugo; WILSON, Marcos; GODOY, Roberto. Guerra Santa nas Malvinas: história de uma derrota. São Paulo: EMW Editores, 1983.

CARDOSO, Fernando Henrique; FALETTI, Enzo. Dependência e desenvolvimento na América Latina. Rio de Janeiro: Zahar, 1970. 


\section{NEIBA}

VOLUME VII

Dossiê: SimpoRI 2018

2018

CARPEAUX, Otto Maria. A Batalha da América Latina. Rio de Janeiro: Civilização Brasileira, 1965.

CARRIL, Bonifácio del. La cuestión de las Malvinas. Buenos Aires: Hyspamerica, 1986.

CASTRO, Fernando. Um projeto de Diplomacia Cultural para a República: a Revista Americana e a construção de uma nova visão continental. Revista Brasileira de História. São Paulo: v. 32, nº3, pp. 301-324, 2012.

(org.). Raça: trajetórias de um conceito. Rio de Janeiro: Ponteio, 2014.

CHAUÍ, Marilena. Brasil: mito fundador. São Paulo: Perseu Ábramo, 2000.

CERVO, Amado (org.). O Desafio Internacional. Brasília: UnB, 1994.

CONSANI, Norberto; SEPULVEDA, Alberto; ZERAOUI, Zidane. Las relaciones internacionales de Argentina, Chile y México. Buenos Aires: Latinoamericano, 2007.

COUTINHO, Marcelo. Crises Institucionais e Mudanças Políticas na América do Sul. Rio de Janeiro: Tese de Doutorado do IUPERJ, 2008. DUARTE, Paulo de Queiróz. O Conflito nas Malvinas. Rio de Janeiro: Bibliex, 1986.

FAUSTO, Bóris; DEVOTO, Fernando. Brasil e Argentina: Um ensaio de história comparada (1850-2002). São Paulo: $34,2004$.

FERRER. Aldo. A economia argentina. Rio de Janeiro: Campus, 2005.

FONTANA. Joseph. História dos Homens. Santa Catarina: Edusc, 1998.

FURTADO, Celso. Formação Econômica do Brasil. Rio de Janeiro: Cia das Letras, 2004.

GELLNER, Ernest. Nações e Nacionalismo. São Paulo: Gradiva, 1997.

GOMES, Ângela. Estudos Históricos: Cpdoc 20 anos depois. Rio de Janeiro: FGV, 1994.

GOMEZ, Federico Martín. Sin guerra, las Malvinas ya serían nuestras. Buenos Aires: Boletim informativo do IRI/UNLP, 2009.

GONÇALVES, Williams (org.). Argentina e Brasil: vencendo os preconceitos. Rio de Janeiro: Revun: 2009.

GROUSSAC, Paul. Las Islas Malvinas. Buenos Aires: Biblioteca Popular, 1936.

HALE, Charles A. "As ideias políticas e sociais na América Latina, 1870-1930". In: BETHELL, Leslie (org.). História da América Latina de 1870 a 1930. Vol. IV. Tradução Geraldo Gerson de Souza. São Paulo: Editora da Universidade de São Paulo, Brasília, DF: Fundação Alexandre de Gusmão, 2009. pp. 331-352.

HECKER, Alexander. A História política e seu historiador. In: Entre o passado e o Futuro. São Paulo: Revista da USP, 2005. HERZ, Mônica. Organizações Internacionais. Rio de Janeiro: Elsevier, 2004.

HOBSBAWN, Eric. A Era dos Impérios. Rio de Janeiro: Paz e Terra, 1988. 


\section{NEIBA}

Nações e Nacionalismo desde 1780. Rio de Janeiro: Paz e Terra, 1991.

Sobre a História. São Paulo: Companhia das Letras, 1998.

HOFMEISTER, Wilhem. Liderazgo político en América Latina. Rio de Janeiro: Konrad Adenuaer, 2002.

JAGUARIBE, Hélio. Novo Cenário Internacional. Rio de Janeiro: Guanabara, 1986.

Reflexiones sobre el Atlántico sur: América Latina y el Brasil ante la desarticulación del sistema interamericano.

Rio de Janeiro, 1988.

KOCKA, Jurgen. Comparisonandbeyond. In:HistoryandTheory, v.42, pp.39-44, 2003.

KOSELECK, Reinhart. Futuro passado. Rio de Janeiro: Contraponto, 1994.

LAFER, Celso; PENA, Félix. Argentina e Brasil no sistema de relações internacionais. São

Paulo: Duas Cidades, 1975.

LANUS, Juan. De Chapueltec al Beagle. Buenos Aires: Hyspamerica, 1986.

LUNA, Félix. Golpes Militares. Buenos Aires: Planeta, 2001.

MAZZINI, Pasquale. Sobre la nacionalidad. Madrid: Tecnos, 1985.

MELLO, Leonel Itaussu. Argentina e Brasil: a balança de poder no Cone Sul. São Paulo: Annablume, 1996.

NAVARRO, Marysa. Evita. Buenos Aires: Edhasa, 2011.

NEUMAN, Stephanie. InternationalRelationsTheoryandtheThird World. Nova York: St. Martin's Press, 1998.

NOVARO, Marcos; PALERMO, Vicente. A ditadura militar Argentina (1976-1983): do golpe de Estado à restauração democrática. São Paulo: USP, 2007.

NEVES, André Luiz. Teoria das Relações Internacionais. Petrópolis: Vozes, 2009.

PALÁCIOS, Alfredo. Lasislas Malvinas. Buenos Aires: Claridad, 1934.

PASCUAL, Alejandra.Terrorismo de Estado. Brasília: UnB, 1997.

PASO, Leonardo. Raíces históricas de la dependencia argentina. Buenos Aires: Centro Editor de América Latina, 1985.

PIEL, Jean (org.). Critique Amerique Latine. Paris: Editions de Minuit, 1977.

POLANIY, Karl. A grande transformação. Rio de Janeiro: Campus, 1997.

RAPOPORT, Mario. El Laberinto argentino. Buenos Aires: Universitaria, 1997. 


\section{NEIBA}

A guerra das Malvinas e a política exterior argentina. Buenos Aires: Ediciones Macchi, 1997.

REMOND, René. Por uma História Política. Rio de Janeiro: UFRJ/FGV, 1996.

RENAN, Ernest. O que é uma nação? Rio de Janeiro: Cadernos de Pós da UERJ, 1997.

ROMERO, Luis Alberto. História Contemporánea de la Argentina. Buenos Aires: Fondo de Cultura Económica, 2006.

ROUQUE, Alain; TOUCHARD, Jean. La Republique Argentine. Paris: Press Universitairies de France, 1972.

RUDZIT, Gunther; NOGAMI, Otto. Segurança e Defesa nacional: conceitos básicos para uma análise. In: Revista Brasileira de Política Internacional. 53 (1): 5-24, 2010.

SAID, Edward. Cultura e Imperialismo. Rio de Janeiro: Companhia das Letras, 2000.

SÁ. Maria Elisa Noronha de (org.). Civilização e Barbárie: a construção da ideia de nação em Brasil e Argentina. Rio de Janeiro: Garamond, 2012.

História intelectual latino-americana: itinerários, debates e perspectivas. Rio de Janeiro: Ed. PUC-

Rio, 2016.

SANTOS, Raquel Paz dos. La diplomacia cultural como un nuevo elemento para pensar las relaciones argentino-brasileñas (1930-1954). In: CD del III Congreso de Relaciones Internacionales de la Universidad Nacional de la Plata: La Plata, 2006.

SARAIVA, Miriam Gomes. As estratégias de cooperação sul-sul nos marcos da política externa brasileira. Revista Brasileira de Política Internacional: volume 50, no 2, 2007.

SARLO, Beatriz. Tempo Passado. Rio de Janeiro: Companhia das Letras, 2007.

SARMIENTO. Domingo Fausto. Conflictos e armonías de las razas en América. 1883.

SEIXLACK, Alessandra Gonzalez de Carvalho. Discursos políticos sobre a raça indígena na Argentina: Domingo Faustino Sarmiento e o conflito das raças na América. In: ASCENSO, João Gabriel da Silva e CASTRO, Fernando Luiz Vale (orgs.). Raça: trajetórias de um conceito- histórias do discurso racial na América Latina. Rio de Janeiro: Ponteio, 2014.

SILVA, Francisco Carlos Teixeira da; COSTA, Darc (orgs.). Mundo Latino e Mundialização. Rio de Janeiro: Mauad, 2005.

SIRKYS, Alfredo. A Guerra da Argentina. São Paulo: Record, 1982.

SMITH, William C. Reflexões sobre a economia política da dominação autoritária e a reorganização capitalista na Argentina contemporânea. Belo Horizonte: UFMG, 1983.

TERRAGNO, Rodolfo. Falklands. Buenos Aires: Ediciones De la Flor, 2002.

VERBITSKY, Horácio. Malvinas: La última batalla de la Tercera Guerra Mundial. Buenos Aires: Sudamericana, 2002. 


\section{NEIBA}

VOLUME VII

Dossiê: SimpoRI 2018

VEYNE, Paul. O inventário das diferenças. São Paulo: Brasiliense, 1983.

WEST, Nigel. La guerra secreta por las Malvinas. Buenos Aires: Sudamericana, 1997.

WHELING, Arno. A invenção da História. Rio de Janeiro: Cia das Letras, 1995. 